\title{
BMJ Open Attitudes, stressors and work outcomes related to the COVID-19 pandemic among dental assistants in Germany: a cross-sectional study
}

\author{
Annegret Dreher (D) , ${ }^{1}$ Reinhard Pietrowsky, ${ }^{2}$ Adrian Loerbroks (D) ${ }^{1}$
}

To cite: Dreher A, Pietrowsky R, Loerbroks A. Attitudes, stressors and work outcomes related to the COVID-19 pandemic among dental assistants in Germany: a cross-sectional study. BMJ Open 2021;11:e045881. doi:10.1136/ bmjopen-2020-045881

- Prepublication history and additional supplemental material for this paper are available online. To view these files, please visit the journal online (http://dx.doi.org/10.1136/ bmjopen-2020-045881).

Received 15 0ctober 2020 Accepted 27 August 2021

Check for updates

(c) Author(s) (or their employer(s)) 2021. Re-use permitted under CC BY-NC. No commercial re-use. See rights and permissions. Published by BMJ.

${ }^{1}$ Institute of Occupational, Social and Environmental Medicine, Centre for Health and Society, Faculty of Medicine, University of Duesseldorf, Dusseldorf,

Germany

${ }^{2}$ Institute of Experimental Psychology, Department of Clinical Psychology, University of Duesseldorf, Dusseldorf, Germany

Correspondence to Dr Adrian Loerbroks; adrian.loerbroks@uniduesseldorf.de

\section{ABSTRACT}

Objectives The COVID-19 pandemic has posed great challenges to medical professionals worldwide. Dental assistants (DAs) are at exceptionally high risk of infection with SARS-CoV-2 due to frequent and close patient contact and involvement in various high-risk dental procedures. This study aimed to investigate attitudes, stressors and work outcomes among DAs from all over Germany at the peak of cases in spring 2020.

Design Cross-sectional study. Descriptive analysis and logistic regression.

Setting Dental, maxillofacial surgery and orthodontic practices across Germany, April 2020.

Participants Participants aged 18 years and above and currently working as DAs in Germany.

Primary and secondary outcome measures A selfdevised online questionnaire was employed comprising questions on SARS-CoV-2-related attitudes, stressors and work outcomes. Validated scales assessed symptoms of depression and anxiety.

Results Among 1481 participating DAs (median age 35 years, $98.4 \%$ female, $91.8 \%$ working in dental practices), major stressors were uncertainty about the pandemic's temporal scope (97.9\% agreement, $n=1450)$, uncertainty about one's financial situation $(87.8 \%, \mathrm{n}=1301)$, uncertainty about how to act correctly $(87.6 \%, \mathrm{n}=1298)$ and thoughts about a possible infection during work (83.8\%, $\mathrm{n}=1241)$. Forty-two per cent of DAs ( $n=622$ ) felt sufficiently prepared for dealing with patients with SARS-CoV-2. Only $17.5 \%(n=259)$ agreed that material for personal protection was sufficiently available. Multivariable logistic regression analyses suggested that working in a dental practice, compared with orthodontic and maxillofacial surgery practices, was significantly associated with uncertainty about one's financial situation (OR $2.13(95 \% \mathrm{Cl} 1.33$ to 3.44$)$ ) and with the reported availability of personal protective equipment (PPE) $(0.55$ (0.36 to 0.84)).

Conclusions Training about correct behaviour of DAs during future infectious disease outbreaks is needed, especially for DAs working in dental practices. In the future, it will also be necessary to strengthen supply chains to ensure that PPE is sufficiently available in a timely manner.

\section{INTRODUCTION}

In late 2019, the SARS-CoV-2 was first described to cause respiratory symptoms in humans. ${ }^{1}$ The disease, referred to as COVID-19, has since spread rapidly causing

\section{STRENGTHS AND LIMITATIONS OF THIS STUDY}

$\Rightarrow$ This study is the first to investigate a broad range of attitudes, stressors and work outcomes among dental assistants during the SARS-CoV-2 pandemic.

$\Rightarrow$ It was conducted during the peak time of the SARSCoV-2 pandemic in spring 2020 in Germany and therefore with only little potential for recall bias.

$\Rightarrow$ The study instrument was developed together with experts of the German Association of Medical Professionals who have not only worked as dental assistants themselves for many years but are in close and regular contact with dental assistants from all over Germany.

$\Rightarrow$ Nevertheless, the psychometric properties of the study instrument remain unclear.

$\Rightarrow$ Due to the cross-sectional design, no causal relationships can be determined.

a worldwide pandemic. ${ }^{2}$ By the beginning of August 2020, over 19000000 cases and 730000 deaths had been confirmed worldwide including more than 210000 cases in Germany. $^{3}$

The SARS-CoV-2 pandemic poses new occupational health risks especially for health workers including, among others, an infection with the virus at work, skin disorders from the use of personal protective equipment (PPE) or psychological distress. ${ }^{4}$ According to estimates of the UK Office for National Statistics, dental assistants (DAs), dental hygienists and dentists are among the professional groups with the highest risk of infection. ${ }^{5}$ These calculations were based on DAs' daily exposure to the disease combined with close physical proximity to patients. Previous studies have suggested multiple routes of SARS-CoV-2 transmission in dental care including coughing and sneezing of patients causing droplets that might be inhaled or direct contact transmission with oral, nasal and eye mucous membranes. ${ }^{6} 7$ Contaminated dental equipment, contaminated 
surfaces and micro-injuries caused by sharps were also discussed as possible transmission routes. ${ }^{8}$ Many dental procedures have been shown to produce aerosols and contaminated droplets, ${ }^{9}$ in particular from periodontal treatments, which could result in possible contamination of the dental staff's faces. ${ }^{10}$

The SARS-CoV-2 pandemic also poses considerable financial challenges for many dental practices. ${ }^{11}$ The National Association of Statutory Health Insurance Dentists published a statement in March 2020 according to which the assurance of dental care had to be maintained even in times of steady spread of SARS-CoV-2. ${ }^{12}$ The statement mentioned a fundamental obligation of dentists to provide care. Practice closures ordered by health authorities were explicitly excluded. However, studies report that many dentists have either closed their practices ${ }^{11}{ }^{13}$ or considered closing their practices. ${ }^{14}$ Some considered reducing working hours. ${ }^{13}$ These observations go along with the observation that a high proportion of patients are anxious about the current pandemic and therefore cancel their appointments. ${ }^{13} 15$ Consequently, the number of non-urgency visits has decreased sharply, implying a loss of an important source of income for dental practices. ${ }^{16}$

First studies have shed light on the psychological effects of the COVID-19 pandemic on dental staff. An Italian study by Consolo $e t a l^{13}$ among staff in the areas most affected by the pandemic found that $85 \%$ were worried of contracting the infection during their working time. Almost half of the dental staff reported feelings of anxiety and fear. In a study of 338 dentists and dental hygienists from Israel, elevated levels of psychological distress during the COVID-19 pandemic were found among $11.5 \%$ of participants and were associated with having an underlying disease and a higher subjective overload. ${ }^{17}$ Being in a relationship and high self-efficacy were associated with less psychological distress from the COVID-19 pandemic. $^{17}$

Outside of these few studies, there is very little research on COVID-19-related distress among dental staff. The above-mentioned studies focused on dentists and dental hygienists, yet no studies have investigated such stressors among DAs. In Germany, over 215000 DAs work in dental, orthodontic or maxillofacial surgery practices. ${ }^{18} 19$ DAs carry out, among others, reception tasks, are responsible for the cleaning of instruments and assist during dental procedures. ${ }^{20}$ Involvement in dental procedures such as the use of ultrasonic scales, air water syringes or high-speed hand pieces puts DAs at exceptionally high risk of contraction of SARS-CoV-2 as these procedures commonly generate aerosols ${ }^{21}$ and SARS-CoV-2 has been found to be viable in aerosols for at least 3 hours. ${ }^{22}$ Furthermore, the published studies on stressors among dental staff have been of limited scope. They offer little potential for interventions because the causes and types of stressors have not been investigated in detail.

This study therefore aimed to first, investigate a broad range of pandemic-related attitudes, stressors and work outcomes among DAs in Germany; and second, to identify possible determinants. Along with assessing determinants included in previous studies, this study also included determinants that have not been investigated in this context so far (eg, caring for underage children, level of education, place of work).

\section{METHODS}

\section{Study design}

A cross-sectional study was conducted. The study was conducted in accordance with the Declaration of Helsinki. All participants gave electronic consent to participate in the study.

\section{Study procedure and population}

An online questionnaire for DAs was posted by the Association of Medical Professionals (Verband medizinischer Fachberufe e.V.) on their web page and social media from 7 April to 14 April 2020. The questionnaire had the potential to reach out to members and followers of the association from all over Germany. Currently, approximately 12000 people follow the social media channels of the association, but the exact number of addressees could not be determined. Participant inclusion criteria for all further analyses were age of majority (18 years and older) and current employment as a DA.

\section{Questionnaire}

No validated questionnaires on stressors and attitudes of medical staff during a pandemic situation were available at the time of study conception. Therefore, the authors of this study developed a questionnaire comprised of items on sociodemographic characteristics and three pandemic-related topics: pandemic-related attitudes (five items), pandemic-related stressors (eight items) and pandemic-related work outcomes (three items) (see online supplemental file).

Participants were asked to express their agreement to given statements using a 4-point Likert scale. Depression and anxiety were measured using the German-language two-item versions of the Patient Health Questionnaire (PHQ-2) ${ }^{23}$ and the Generalized Anxiety Disorder Questionnaire (GAD$2),{ }^{24}$ respectively. These tools have demonstrated sufficient internal consistency (PHQ-2 $\alpha=0.83,{ }^{23}$ GAD-2 $\alpha=0.77^{25}$ ) and convergent validity with established measures such as PHQ-7 or the Hospital Anxiety and Depression Scale depression score $^{23}$ and GAD-7, ${ }^{24}$ respectively. While both instruments' ability to differentiate between specific diseases patterns may be limited, they are sufficient for screening for any depressive disorder and any form of anxiety disorder. ${ }^{23} 24$ Pandemic-related items were discussed and refined together with experts of the Association of Medical Professionals that represents DAs in Germany and acts nationwide. The association's head office is located in Bochum, North RhineWestphalia. Experts of the association have not only worked as DAs themselves for many years but are in regular and close contact with DAs all over Germany through educational 
events, phone calls and their own previous surveys among members. Items on the perceived risk of infection compared with the general population were modified from Liao et $a t^{26}$ and de Zwart $e t a l,{ }^{27}$ and items on preparedness and availability of PPE were adapted from $\mathrm{Hu}$ et $a .^{28}$

\section{Statistical analysis}

Due to the exploratory nature of this study, no a priori hypothesis was established before the analysis. To address the first research aim, describing SARS-CoV-2-related attitudes, stressors and work outcomes among DAs in Germany, descriptive analyses were run for all variables. Absolute numbers and percentages were displayed for categorical variables, and median and IQR for the numerical age variable (as age was not normally distributed). To examine determinants of SARS-CoV-2-related attitudes and stressors and therefore to identify possible subgroups at increased risk of feeling burdened, that is, the second research aim, logistic regression analysis was performed to investigate possible associations with sociodemographic variables, depressive symptoms and anxiety. All pandemic-related outcome variables were dichotomised from their original 4-point answer scale into either $1=$ 'agree' or $0=$ 'disagree'. As recommended, cut-off values of $\geq 3$ were used to categorise participants' PHQ-2 and GAD-2 sum scores into 'major depression' and 'generalised anxiety disorder', respectively. ${ }^{23}{ }^{24}$ Two different multivariable models were run: for pandemic-related attitudes and stressors, the multivariable model included all sociodemographic variables except sex (see table 1) and included a binary variable for depression and one for anxiety disorder. For pandemic-related work outcomes, the multivariable model included age and place of work. For a sensitivity analysis, the multivariable models for pandemic-related attitudes and stressors were run without adjusting for depression and anxiety disorder. Sex was excluded from all regression analyses due to the small proportion of non-female participants $(n=24,1.7 \%)$. Associations were reported as ORs with respective $95 \%$ CIs. All analyses were carried out using IBM SPSS Statistics V.25. ${ }^{29}$

\section{Patient and public involvement}

There was no patient or public involvement in this study.

\section{RESULTS}

A total of 1487 DAs participated in the survey. Six DAs had missing information on their year of birth and were excluded, leaving a remainder $1481 \mathrm{DAs}$ for statistical analysis (median age 35 years (IQR: 28-42), 98.4\% female). The majority worked in dental practices (91.8\%). As much as $13.4 \%$ reported suspected or confirmed SARS-CoV-2 cases among their friends and family, $11.3 \%$ among their colleagues and only four participants $(0.4 \%)$ reported having been infected themselves. The variable 'having been infected oneself' was therefore excluded as determinant from the logistic regression modelling due to too few cases. Characteristics of the study population are displayed in table 1 .
Table 1 Sociodemographic characteristics of participating dental assistants $(n=1481)$

\begin{tabular}{|c|c|}
\hline Characteristics & $n(\%)$ \\
\hline \multicolumn{2}{|l|}{ Sex } \\
\hline Male & $23(1.6)$ \\
\hline Female & $1457(98.4)$ \\
\hline Non-binary & $1(0.1)$ \\
\hline Age, median (IQR) & $35(28-42)$ \\
\hline $18-30$ & $513(34.6)$ \\
\hline $31-40$ & $506(34.2)$ \\
\hline 41 and older & 462 (31.2) \\
\hline \multicolumn{2}{|l|}{ Permanent partner } \\
\hline Yes & 1239 (83.7) \\
\hline No & $242(16.3)$ \\
\hline \multicolumn{2}{|c|}{ Children under care in same household } \\
\hline Yes & $578(39.0)$ \\
\hline No & $903(61.0)$ \\
\hline \multicolumn{2}{|c|}{ Highest level of education } \\
\hline Low $^{\star}$ & $156(10.5)$ \\
\hline Intermediate $†$ & 1065 (71.9) \\
\hline High $\ddagger$ & $258(17.4)$ \\
\hline Other & $2(0.1)$ \\
\hline \multicolumn{2}{|l|}{ Place of work } \\
\hline Dental practice & $1360(91.8)$ \\
\hline Other§ & $121(8.2)$ \\
\hline \multicolumn{2}{|l|}{ Self-rated health } \\
\hline Very good & $380(25.7)$ \\
\hline Good & $856(57.8)$ \\
\hline Moderate & 225 (15.2) \\
\hline $\mathrm{Bad}$ & $18(1.2)$ \\
\hline Very bad & $2(0.1)$ \\
\hline
\end{tabular}

Suspected or confirmed SARS-CoV-2 cases among friends and family

$\begin{array}{lr}\text { Yes } & 198(13.4) \\ \text { No } & 1283(86.6)\end{array}$

Suspected or confirmed SARS-CoV-2 cases among colleagues

$\begin{array}{lr}\text { Yes } & 167(11.3) \\ \text { No } & 1314(88.7)\end{array}$

Own previous infection with SARS-CoV-2

$\begin{array}{lc}\text { Yes } & 4(0.4) \\ \text { No } & 1477(99.7) \\ \text { Major depressionף } & \\ \text { Yes } & 580(39.2) \\ \text { No } & 901(60.8) \\ \begin{array}{l}\text { Generalised anxiety disorder } \\ \text { Yes }\end{array} & 723(48.8)\end{array}$

Continued 
Table 1 Continued

\begin{tabular}{|c|c|}
\hline Characteristics & n (\%) \\
\hline No & 758 (51.2) \\
\hline $\begin{array}{l}\text { *Low: secondary } \\
\text { Volksschulabschlu } \\
\text { †Intermediate: sec } \\
\text { Reife', 'Realschula } \\
\text { †High: general qu } \\
\text { or entrance qualifi } \\
\text { sciences ('Fachho } \\
\text { §Other individual } \\
\text { and maxillofacial } \\
\text { †According to the } \\
{ }^{\star} \text { According to the }\end{array}$ & $\begin{array}{l}\text { ('Haupt-/ } \\
\text { icate ('Mittlere } \\
\text { fe'). } \\
\text { rance ('Abitur') } \\
\text { s of applied } \\
\text { tic practices } \\
\text { ire-2. } \\
\text { der Scale-2. }\end{array}$ \\
\hline
\end{tabular}

\section{Descriptive analysis}

Absolute numbers and percentages of pandemic-related attitudes, stressors and work outcomes are shown in table 2. Most DAs $(83.8 \%)$ agreed that their individual risk of SARS-CoV-2 contraction was higher compared with a person of same age and sex of the general population. Less than half of all DAs felt sufficiently informed (49.6\%) and prepared $(42.0 \%)$ by their employer for dealing with patients with SARS-CoV-2. Major stressors were uncertainty about the temporal scope of the pandemic (97.9\% agreement), uncertainty about one's financial situation $(87.8 \%)$, uncertainty about how to act correctly $(87.6 \%)$ and thoughts about a possible infection during working hours $(83.8 \%)$. Only $17.5 \%$ agreed that enough material for personal protection was available for them to use.

\section{Logistic regression results}

Pandemic-related attitudes

Results from the logistic regressions on pandemic-related attitudes are displayed in table 3.

Belonging to the oldest age group was significantly associated with an increased perceived risk of infection (OR 1.64 (95\% CI 1.13 to 2.39)). Participants' level of education was negatively correlated with reports of an increased pandemic-related workload (intermediate education 0.68 (95\% CI 0.48 to 0.98$)$, high education 0.60 (95\% CI 0.38 to 0.93$)$ ). DAs with good self-rated health were more likely to feel sufficiently prepared for dealing with patients with SARS-CoV-2 (1.54 (95\% CI 1.12 to 2.12)), whereas DAs who reported suspected or confirmed cases among their colleagues felt less prepared (0.63 (95\% CI 0.44 to 0.91$)$ ). An inverse association was also found between suspected or confirmed SARS-CoV-2 cases among friends or family and the feeling of being sufficiently protected by available PPE (0.61 (95\% CI 0.40 to 0.93$))$.

\section{Pandemic-related stressors}

Caring for children was positively associated with uncertainty about correct behaviour (1.52 (95\% CI 1.04 to 2.21), see table 4).

In contrast, DAs with good self-rated health felt less uncertain about correct behaviour $(0.35$ (95\% CI 0.18 to 0.69$))$. DAs older than 41 years $(0.63$ (95\% CI 0.43 to $0.93))$ and those with better self-rated health $(0.39(95 \%$ CI 0.22 to 0.70$)$ ) were less likely to feel burdened about thoughts of contraction at their workplace. DAs working in dental practices were more likely to report feeling burdened by uncertainty about their financial situation (2.13 (95\% CI 1.33 to 3.44)) and the temporal scope of the pandemic (2.56 (95\% CI 1.01 to 6.50$)$ ) than those working for other employers. The feeling of not being able to let patients down was significantly associated with suspected or confirmed SARS-CoV-2 cases among friends and family (1.56 (95\% CI 1.07 to 2.29$)$ ).

DAs who screened positive for major depression or generalised anxiety disorder almost consistently showed worse outcomes, for example, greater odds of feeling uncertain about how to act correctly (depression 2.27 (95\% CI 1.45 to 3.56 ), anxiety 2.26 (95\% CI 1.53 to 3.36 )) and lower odds of feeling sufficiently prepared for dealing with patients with SARS-CoV-2 (depression $0.62(95 \%$ CI 0.49 to 0.80 ), anxiety 0.62 (95\% CI 0.49 to 0.79 ) ).

\section{Pandemic-related work outcomes}

DAs within the age group of 31-40 years had lower odds of reporting that enough materials were available for personal protection for them to use $(0.71$ (95\% CI 0.51 to 0.98$)$ ). Working in a dental practice was significantly associated with a feeling that care for patients with other diseases is suffering (1.99 (95\% CI 1.36 to 2.90)) and decreased odds of available materials for personal protection $(0.55$ (95\% CI 0.36 to 0.84$))$.

\section{Sensitivity analysis}

When models were not adjusted for anxiety/depression, similar results were observed for almost all outcomes. The effect estimates for self-rated health were the only ones that constantly decreased by $0.1-0.2$ points for all SARS-CoV-2-related stressors and increased by $0.1-0.2$ points for the feeling of being sufficiently prepared and informed about dealing with patients with SARS-CoV-2.

\section{DISCUSSION}

This study presents the results of a cross-sectional investigation of attitudes, stressors and work outcomes among DAs in Germany during the first peak of the SARS-CoV-2 pandemic in spring 2020. It is the first study to investigate a broad range of stressors among DAs during the SARS-CoV-2 pandemic. This study found very high agreement with many stressors (eg, uncertainty about contact persons, uncertainty about the childcare situation), with major stressors being the uncertainty about the pandemic's temporal scope and financial implications. The data suggest a low level of preparedness of DAs who experienced great uncertainty about how to act correctly, an alarming lack of PPE and frequent worries about a possible own infection.

The great uncertainty about their financial situation may stem from the commonly low wages among DAs in Germany: DAs' median monthly wage in Germany before 
Table 2 Prevalence of SARS-CoV-2-related attitudes, stressors and work outcomes among $n=1481$ dental assistants

\begin{tabular}{|c|c|c|c|c|c|c|}
\hline & \multicolumn{2}{|c|}{$\begin{array}{l}\text { Dichotomised scale for regression } \\
\text { analysis }\end{array}$} & \multicolumn{4}{|c|}{ Original 4-point Likert scale } \\
\hline & $\begin{array}{l}\text { Agree } \\
\mathrm{n}(\%)\end{array}$ & $\begin{array}{l}\text { Disagree } \\
\mathrm{n}(\%)\end{array}$ & $\begin{array}{l}\text { Strongly agree } \\
\mathrm{n}(\%)\end{array}$ & $\begin{array}{l}\text { Agree } \\
\mathrm{n}(\%)\end{array}$ & $\begin{array}{l}\text { Disagree } \\
\mathrm{n}(\%)\end{array}$ & $\begin{array}{l}\text { Strongly } \\
\text { disagree } \\
\mathrm{n}(\%)\end{array}$ \\
\hline \multicolumn{7}{|l|}{ SARS-CoV-2-related attitudes } \\
\hline $\begin{array}{l}\text { The risk of contracting SARS-CoV-2 is } \\
\text { higher for me than for a person of same } \\
\text { age and sex from the general population }\end{array}$ & $1263(85.3)$ & $218(14.7)$ & $870(58.7)$ & $393(26.5)$ & $166(11.2)$ & $52(3.5)$ \\
\hline $\begin{array}{l}\text { I feel sufficiently informed about dealing } \\
\text { with patients with SARS-CoV- } 2 \text { by my } \\
\text { employer }\end{array}$ & $735(49.6)$ & $746(50.4)$ & $160(10.8)$ & $575(38.8)$ & $488(33.0)$ & $258(17.4)$ \\
\hline $\begin{array}{l}\text { I feel sufficiently prepared for dealing } \\
\text { with patients with SARS-CoV-2 by my } \\
\text { employer }\end{array}$ & $622(42.0)$ & $859(58.0)$ & $99(6.7)$ & $523(35.3)$ & $520(35.1)$ & $339(22.9)$ \\
\hline \multicolumn{7}{|l|}{ SARS-CoV-2-related stressors } \\
\hline $\begin{array}{l}\text { I am burdened by uncertainty about the } \\
\text { temporal scope of the crisis }\end{array}$ & $1450(97.9)$ & $31(2.1)$ & $1021(68.9)$ & $429(29.0)$ & $29(2.0)$ & $2(0.1)$ \\
\hline $\begin{array}{l}\text { I am burdened by uncertainty about my } \\
\text { financial situation during the crisis }\end{array}$ & $1301(87.8)$ & $180(12.2)$ & $852(57.5)$ & $449(30.3)$ & $141(9.5)$ & $39(2.6)$ \\
\hline $\begin{array}{l}\text { I am burdened by uncertainty about how } \\
\text { to act correctly during the crisis }\end{array}$ & $1298(87.6)$ & $183(12.4)$ & $617(41.7)$ & $681(46.0)$ & $158(10.7)$ & $25(1.7)$ \\
\hline $\begin{array}{l}\text { I am burdened with thoughts of a } \\
\text { possible infection with SARS-CoV-2 } \\
\text { during working hours }\end{array}$ & $1241(83.8)$ & $240(16.2)$ & $602(40.6)$ & $639(43.1)$ & $196(13.2)$ & $44(3.0)$ \\
\hline \multicolumn{7}{|l|}{ SARS-CoV-2-related work outcomes } \\
\hline $\begin{array}{l}\text { Due to the SARS-CoV- } 2 \text { pandemic, the } \\
\text { care for patients with other diseases has } \\
\text { been suffering }\end{array}$ & $901(60.8)$ & $580(39.2)$ & $241(16.3)$ & $660(44.6)$ & $459(31.0)$ & $121(8.2)$ \\
\hline $\begin{array}{l}\text { My employer takes the SARS-CoV-2 } \\
\text { pandemic seriously }\end{array}$ & $843(56.9)$ & $638(43.1)$ & $324(21.9)$ & $519(35.0)$ & $459(31.0)$ & $179(12.1)$ \\
\hline $\begin{array}{l}\text { At my work all necessary materials for } \\
\text { personal protection from SARS-CoV-2 } \\
\text { are sufficiently available for me }\end{array}$ & $259(17.5)$ & $1222(82.5)$ & $55(3.7)$ & $204(13.8)$ & $527(35.6)$ & $695(46.9)$ \\
\hline
\end{tabular}

*Only for $n=578$ dental assistants with children under care in their household.

taxes for full-time employment equals $€ 2123$ which is substantially lower than the cross-professional median monthly wage in Germany before taxes for full-time employment (€3401)..$^{30}$ Any shortage in payment either resulting from reduced working hours or dismissals is thus highly critical to DAs in making their living. This study also found DAs to feel insufficiently prepared for the SARS-CoV-2 outbreak: only half of the participants reported to feel prepared and not even one in five agreed that there was enough PPE available for them to use in early April 2020, an early stage of the SARSCoV-2 outbreak. In Germany, employers are responsible for the implementation of infection control measures at the workplace according to the Federal Ministry of Labor and Social Affairs. ${ }^{31}$ Specifically for health workers in the context of COVID-19, the WHO recommends employers to carry out workplace risk assessments and to provide timely and accurate information to staff in order 


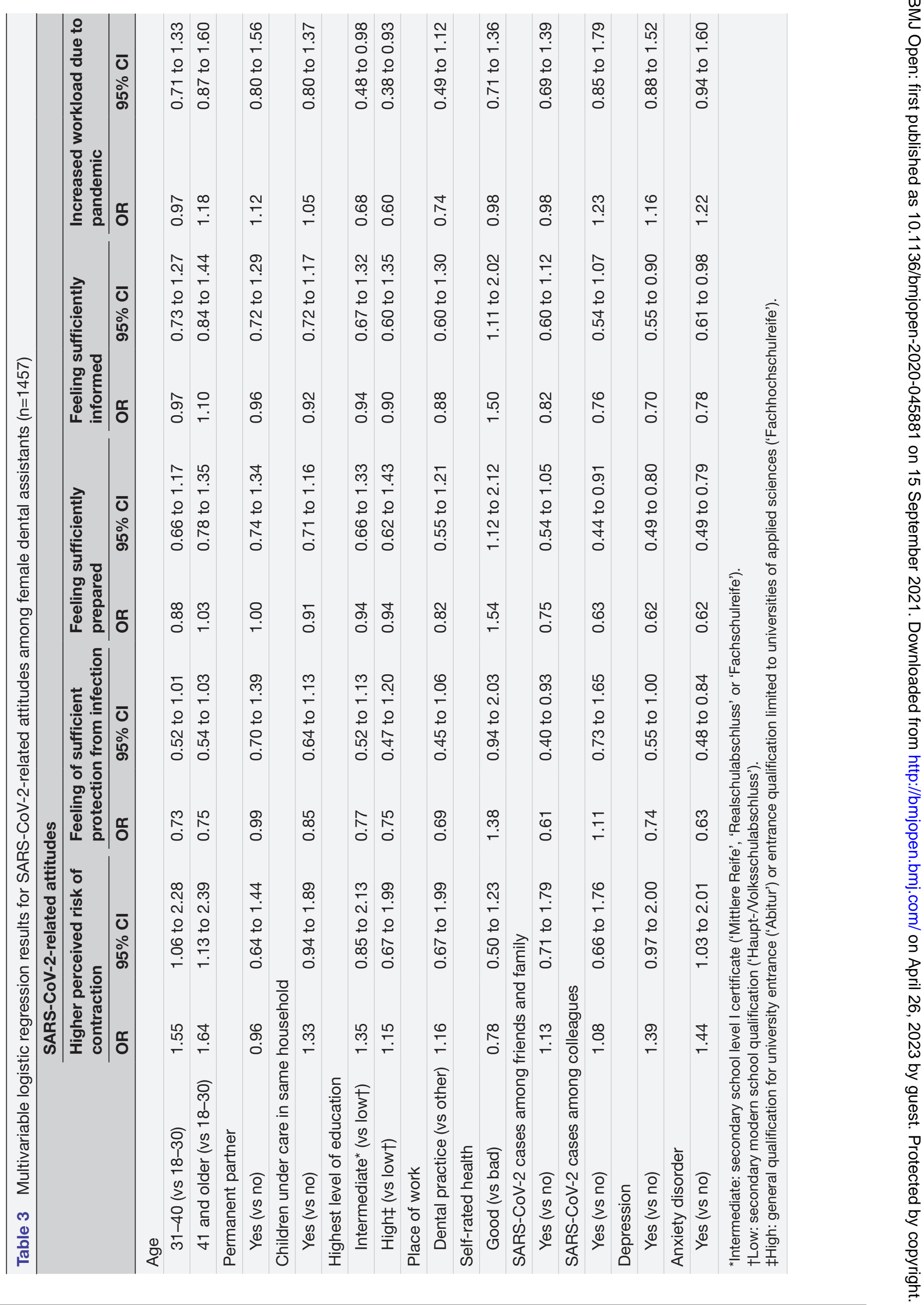




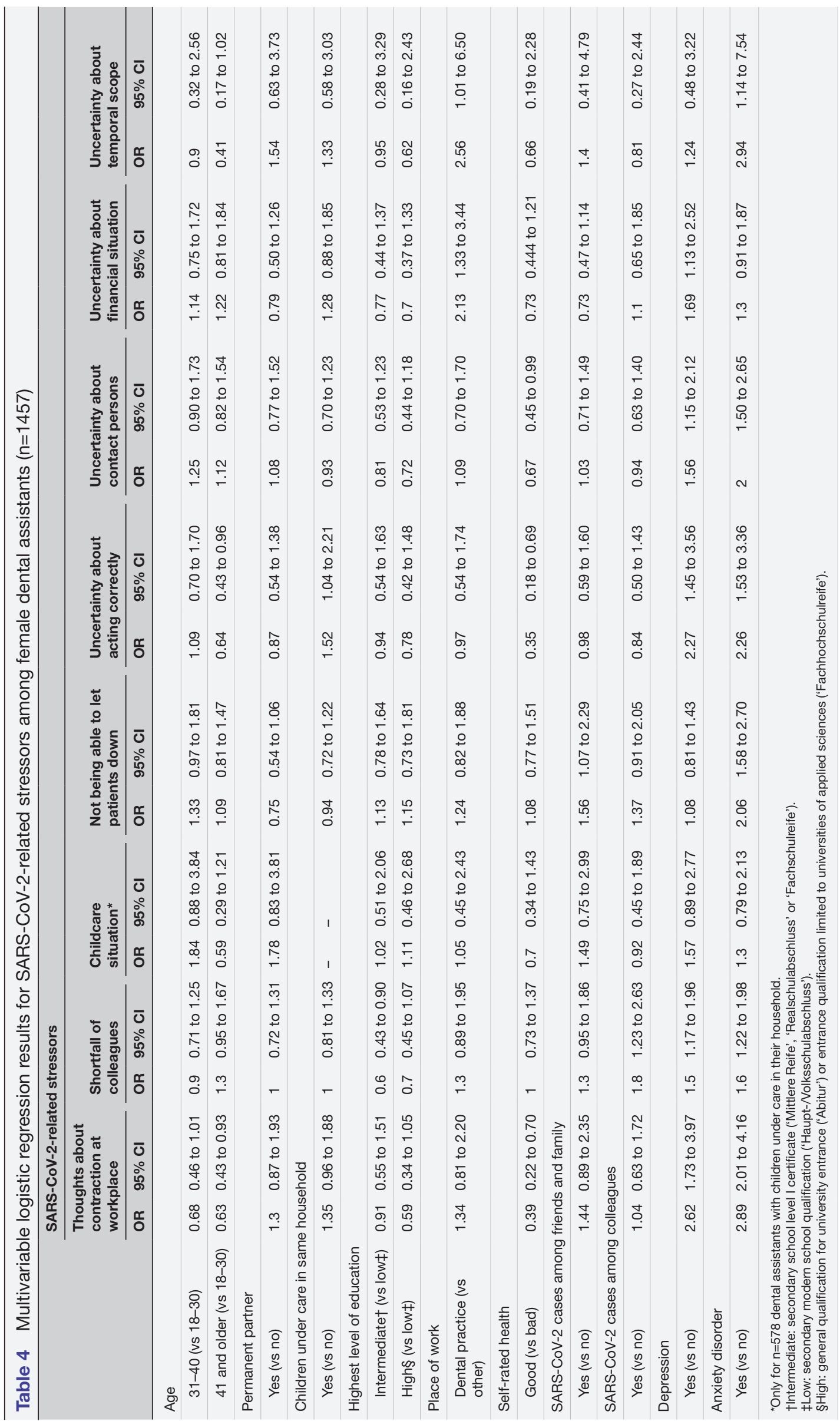


to reduce distress. ${ }^{4}$ Consequently, for future outbreaks, sound education of health workers by their employers is needed about correct behaviour and employers must be able to provide sufficient protective equipment. Given this low level of preparedness, the overall high agreement to the investigated stressors is not surprising. Comparing the results of this study with those of published studies on the psychological effect of the COVID-19 pandemic on dental staff, similar degrees of agreement for being worried about contraction during work $(83.8 \%$ in this sample, $85.1 \%$ in Consolo et $\left.a l^{13}\right)$, and similar degrees of agreement for a lack of PPE $(82.5 \%$ in this sample, $86 \%$ in Consolo et $a l$ ) were found. ${ }^{13}$ The prevalences of depressive symptoms and anxiety were very high in this study. Unfortunately, comparisons with prevalences among DAs in the pre-pandemic era are not possible as such data are lacking. Nevertheless, the findings of the present study are in keeping with certain observations from other studies before and during the SARS-CoV-2 pandemic. Bäuerle et al report that the prevalence of major depression and generalised anxiety disorder among the German general population rose to $14.3 \%$ and $19.7 \%$, respectively, during the pandemic. ${ }^{32}$ A prospective study among DAs in Spain repeatedly investigated generalised anxiety disorder during the SARS-CoV-2 pandemic and found anxiety levels to be highest in the very first weeks of the pandemic. ${ }^{33}$ A study among DAs in Israel from 2019 found high levels of burnout among DAs and revealed that the most stressful work-related factors were, among others, the salary and work hazards. ${ }^{34}$ Supposedly, both conditions have worsened for DAs in Germany during the pandemic and might contribute to the observation of high depression and anxiety levels in this study. Eventually, a study among Taiwanese dental staff found DAs to present the highest values for emotional exhaustion and depersonalisation compared with other dental staff. ${ }^{35}$

In logistic regression analyses, a large number of possible associations were investigated and several of them were found to be statistically significant. Yet, not all significant associations can be explained plausibly, and it cannot be excluded that some significant associations are chance findings. In the following sections, the associations that will be discussed seemed plausible to the authors including after in-depth discussion with experts of the Association of Medical Professionals and with dentists. DAs with better self-rated health were more likely to feel prepared, less uncertain and less concerned about a possible infection. This may be because these DAs feel more confident about their own health and, even in case of an infection, assume milder health consequences. This observation is in line with a study among Polish university students that found about $60 \%$ of the variance of anxiety levels during the SARS-CoV-2 pandemic to be explained by factors including self-rated health. ${ }^{36}$ DAs older than 41 years reported to feel less burdened by thoughts of an infection during working hours. According to the personal experiences of inquired experts (see the Acknowledgements section), older DAs are more likely to spend a significant amount of their working time at the reception and with non-patient tasks compared with their younger colleagues. Anxiety was found to be consistently correlated with different types of stressors. The direction of causality yet remains unclear. A first possible explanation is that individuals who are generally anxious will also worry more about the current pandemic. In contrast, worrying about the pandemic may also lead to symptoms of generalised anxiety disorder. This is supported by the high prevalence of DAs with a screened generalised anxiety disorder $(48.8 \%)$ which is manifold higher than the prevalence of this disorder in the general population. ${ }^{37} \mathrm{~A}$ third possibility is that both constructs (GAD-2 and SARS-CoV-2-related stressors) likely measure the same phenomenon and are not causally linked. The crosssectional study design does not allow for an examination of temporal sequences and thus it remains impossible to clarify which interpretation of findings is most likely.

Working in a dental practice was found to be a significant predictor for uncertainty about the own financial situation during the pandemic, uncertainty about the pandemic's time scope and a lack of available PPE. Other places of work in the study sample were mainly orthodontic and oral and maxillofacial surgery practices. The greater perceived lack of PPE in dental practices compared with other practice types can be explained as follows: therapeutic and diagnostic measures regularly performed in orthodontic practices do not involve drilling with water cooling, which is known for generating aerosols. Therefore, the risk of airborne infection is lower, and less PPE is required. In maxillofacial surgery practices, the standard protective equipment is also more comprehensive than in dental practices as it includes, in addition to gloves and face masks, sterilised coats, hair caps and safety goggles. Maxillofacial surgery practices might thus have had sufficient reserve assets during the countrywide shortage of PPE in early April 2020. A German study among maxillofacial surgery practices found around $40 \%$ of private practices to be satisfied with the supply of PPE by the Federal Associations of Statutory Health Insurance Physicians during the current pandemic. ${ }^{38}$ The differences in terms of financial worries between the different practice types can possibly be explained by wage differences. DAs in dental practices earn less than their colleagues working in orthodontic practices or in oral and maxillofacial surgery practices (gross wage difference about $€ 500^{39}$ ). Another reason may be that the pandemic-related drop in patient numbers possibly affected dental practices to a greater extent than other practice types. Most patients confirmed that they would go to an orthodontic appointment during the SARS-CoV-2 pandemic. $^{15}$

\section{Strengths and limitations}

This study is the first to investigate SARS-CoV-2-related stressors and attitudes among DAs in Germany and collected data during the first peak time of the pandemic, therefore likely capturing high levels of insecurity and stress with a small chance of recall bias. However, the 
results present a snapshot and do not necessarily reflect the current situation (eg, related to the availability of PPE). Due to the online distribution of the study link, no exact response rate could be calculated as it remains unclear how many DAs were reached by the study invitation. A better alternative to estimate the response rate and possible selection bias would have been a defined random sample of study participants. This, on the other hand, would have not made such a timely survey possible. Furthermore, it cannot be assured that the survey link reached all DAs in Germany as it is unlikely that all of them follow the activities of the Association of Medical Professionals. When comparing age and sex characteristics of the study sample with the official numbers of the Federal Agency of Employment, the study sample comprised more participants within the ages $25-54$ years and fewer in other age groups $(<25,55-64,>64$ years $) .{ }^{18}$ It may be that DAs younger than 25 years who have just begun working are less likely to follow the activities of the Association of Medical Professionals and therefore less likely to receive the study link. Older DAs may not be as likely to follow online activities and participate in online research as younger DAs. For this study, a selfdevised questionnaire was used. To be able to conduct the study in a timely manner, the instrument was neither piloted nor validated. The psychometric properties of the questionnaire therefore remain unknown. However, the questionnaire items were-whenever deemed suitablebased on items employed in prior research. Additional items were formulated, and the overall item pool was discussed and refined with experts from the Association of Medical Professionals. These discussions covered the comprehensibility of questionnaire item, the appropriate questionnaire length, the completeness of contents and omissible items. The experts have not only worked as DAs themselves but are in daily contact with thousands of DAs following the Association of Medical Professionals. The expert discussions therefore likely increased the items' validity. Only screening tools for depression and anxiety were used in this study that do not provide clinical diagnoses. Due to the cross-sectional design, this study does not allow to generate insights into temporal sequences and thus possibly causal relationships. Eventually, the 4-point answer scales for the outcome variables in regression analysis were dichotomised in this study. This was chosen for reasons of comprehensibility yet brings along certain loss of information. Alternatively, ordinal regression analysis could have been used without dichotomisation of answer scales. However, under consideration of the solely exploratory approach of this study, it seemed sufficient and more relevant to know whether an individual does feel burdened rather than knowing the odds of the individual belonging to the 'burdened' or 'strongly burdened' group.

\section{CONCLUSIONS}

The results of this study suggest a low level of preparedness among DAs as indicated by high agreement to a broad range of stressors, including great uncertainty about how to act correctly, an alarming lack of PPE and frequent worries about a possible own infection. DAs working in dental practices, those suffering from depressive or anxiety symptoms and those with self-reported poor health were particularly likely to feel burdened during the pandemic. Consequently, sound education about correct behaviour during the SARS-CoV-2 outbreak is needed. In the future, it will also be necessary to ensure that supply chains are secured, and that PPE is available in sufficient quantities in a timely manner.

Acknowledgements The authors are indebted to the Association of Medical Professionals (Verband medizinischer Fachberufe e.V.) for support related to the questionnaire design and participant recruitment and to Mr Norbert Anduleit for setting up the online questionnaire. The authors thank Dr Katrin Eun-Machner and Ms Evgenia Charkina for discussing all findings from their practical perspective as dentists and thank Ms Sylvia Gabel for her practical perspective as dental assistant and head of the Department of Dental Assistants of the Association of Medical Professionals. The authors also thank Dr Sarah Lucht as a native speaker for editing the manuscript.

Contributors AD-literature search, questionnaire design, data collection, data analysis, creation of tables and figures, data interpretation and drafting the first version of the manuscript. $\mathrm{RP}$ - data interpretation, and writing and editing of the final manuscript. $\mathrm{AL}$ - conception of the study, questionnaire design, data interpretation, and writing and editing of the final manuscript.

Funding The authors have not declared a specific grant for this research from any funding agency in the public, commercial or not-for-profit sectors.

Competing interests None declared.

Patient consent for publication Not required.

Ethics approval The Ethics Committee of the Medical Faculty of the University of Dusseldorf approved the study (study number 2020-899).

Provenance and peer review Not commissioned; externally peer reviewed.

Data availability statement The dataset generated and/or analysed during the current study is available in the Zenodo repository, https://doi.org/10.5281/ zenodo.4108608. The minimal dataset needed for replication of the study findings is uploaded as SPSS-file within the Zenodo repository. The DOI is 10.5281/ zenodo.4108608. It will be set to "open access" after acceptance of our manuscript for publication.

Supplemental material This content has been supplied by the author(s). It has not been vetted by BMJ Publishing Group Limited (BMJ) and may not have been peer-reviewed. Any opinions or recommendations discussed are solely those of the author(s) and are not endorsed by BMJ. BMJ disclaims all liability and responsibility arising from any reliance placed on the content. Where the content includes any translated material, BMJ does not warrant the accuracy and reliability of the translations (including but not limited to local regulations, clinical guidelines, terminology, drug names and drug dosages), and is not responsible for any error and/or omissions arising from translation and adaptation or otherwise.

Open access This is an open access article distributed in accordance with the Creative Commons Attribution Non Commercial (CC BY-NC 4.0) license, which permits others to distribute, remix, adapt, build upon this work non-commercially, and license their derivative works on different terms, provided the original work is properly cited, appropriate credit is given, any changes made indicated, and the use is non-commercial. See: http://creativecommons.org/licenses/by-nc/4.0/.

\section{ORCID iDs}

Annegret Dreher http://orcid.org/0000-0002-5007-648X

Adrian Loerbroks http://orcid.org/0000-0003-2795-8684

\section{REFERENCES}

1 Salata C, Calistri A, Parolin C, et al. Coronaviruses: a paradigm of new emerging zoonotic diseases. Pathog Dis 2019;77 doi:10.1093/ femspd/ftaa006 
2 World Health Organization. Virtual press conference on COVID-19, 2020. Available: https://www.who.int/docs/default-source/ coronaviruse/transcripts/who-audio-emergencies-coronaviruspress-conference-full-and-final-11 mar2020.pdf?sfvrsn=cb432bb3_2 [Accessed 24 Mar 2021].

3 European Centre for Disease Prevention and control. COVID-19 situation update worldwide, as of 16 August 2020, 2020. Available: https://www.ecdc.europa.eu/en/geographical-distribution-2019ncov-cases [Accessed 17 Aug 2020].

4 World Health Organization and International Labour Organization. COVID-19: occupational health and safety for health workers: interim guidance 2021

5 Office for National Statistics (UK). Which occupations have the highest potential exposure to the coronavirus (COVID-19)? 2020 Available: https://www.ons.gov.uk/employmentandlabourmarket/ peopleinwork/employmentandemployeetypes/articles/whichoccupat ionshavethehighestpotentialexposuretothecoronaviruscovid19/202005-11 [Accessed 17 Aug 2020].

6 Peng X, Xu X, Li Y, et al. Transmission routes of 2019-nCoV and controls in dental practice. Int $J$ Oral Sci 2020;12:9.

7 Lu C-W, Liu X-F, Jia Z-F. 2019-nCoV transmission through the ocular surface must not be ignored. Lancet 2020;395:e39. doi:10.1016/ S0140-6736(20)30313-5

8 Meng L, Hua F, Bian Z. Coronavirus disease 2019 (COVID-19): emerging and future challenges for dental and oral medicine. $J$ Dent Res 2020;99:481-7.

9 Harrel SK, Molinari J. Aerosols and splatter in dentistry: a brief review of the literature and infection control implications. J Am Dent Assoc 2004:135:429-37.

10 Nejatidanesh F, Khosravi Z, Goroohi H, et al. Risk of contamination of different areas of dentist's face during dental practices. Int J Prev Med 2013;4:611-5.

11 Farooq I, Ali S. COVID-19 outbreak and its monetary implications for dental practices, hospitals and healthcare workers. Postgrad Med J 2020;96:postgradmedj-2020-137781.

12 National Association of Statutory Health Insurance Dentists. SARSCoV-2/COVID-19: actions taken by the dental community to maintain care, 2020. Available: https://www.kzbv.de/massnahmenpaket-derzahnaerzteschaft.1379.de.html [Accessed 26 Jul 2021].

13 Consolo U, Bellini P, Bencivenni D, et al. Epidemiological aspects and psychological reactions to COVID-19 of dental practitioners in the Northern Italy districts of Modena and Reggio Emilia. Int $J$ Environ Res Public Health 2020;17 doi:10.3390/ijerph17103459

14 Ahmed MA, Jouhar R, Ahmed N, et al. Fear and practice modifications among dentists to combat novel coronavirus disease (COVID-19) outbreak. Int J Environ Res Public Health 2020;17 doi:10.3390/ijerph17082821

15 Cotrin P, Peloso RM, Oliveira RC, et al. Impact of coronavirus pandemic in appointments and anxiety/concerns of patients regarding orthodontic treatment. Orthod Craniofac Res 2020;23:455-61.

16 Guo H, Zhou Y, Liu X, et al. The impact of the COVID-19 epidemic on the utilization of emergency dental services. J Dent Sci 2020;15:564-7.

17 Shacham M, Hamama-Raz Y, Kolerman R, et al. COVID-19 factors and psychological factors associated with elevated psychological distress among dentists and dental hygienists in Israel. Int J Environ Res Public Health 2020;17 doi:10.3390/ijerph17082900

18 Statistics of the Federal Employment Agency. Tables, employees by profession (KIdB 2010) (quarterly figures), 2020. Available: https://statistik.arbeitsagentur.de/SiteGlobals/Forms/Suche/ Einzelheftsuche_Formular.html;jsessionid=E387FCBE496EBFAD5425 84FB97ACECA8? $\mathrm{nn}=20894$ \&topic $\mathrm{f}=$ beschaeftigung-sozbe-bo-heft [Accessed 24 Mar 2021].

19 Federal Employment Agency. Dental assistant - brief description. Available: https://berufenet.arbeitsagentur.de/berufenet/faces/index? path=null/suchergebnisse/kurzbeschreibung\&dkz=14704 [Accessed 22 Mar 2021].

20 Federal Employment Agency. Dental assistant - content of activities. Available: https://berufenet.arbeitsagentur.de/berufenet/faces/ index;BERUFENETJSESSIONID=inBORpYNvyPDCMCiw7vXzW3g
UNE8sz80qEmxk0oZW4niVaPFNPfS!1960291816?path=null/ suchergebnisse/kurzbeschreibung/taetigkeitsinhalte\&dkz=14704 [Accessed 24 Mar 2021]

21 Zemouri C, de Soet $\mathrm{H}$, Crielaard W, et al. A scoping review on bio-aerosols in healthcare and the dental environment. PLoS One 2017;12:e0178007.

22 van Doremalen N, Bushmaker T, Morris DH, et al. Aerosol and surface stability of SARS-CoV-2 as compared with SARS-CoV-1. N Engl J Med 2020;382:1564-7.

23 Löwe B, Kroenke K, Gräfe K. Detecting and monitoring depression with a two-item questionnaire (PHQ-2). J Psychosom Res 2005:58:163-71.

24 Kroenke K, Spitzer RL, Williams JBW, et al. Anxiety disorders in primary care: prevalence, impairment, comorbidity, and detection. Ann Intern Med 2007:146:317-25.

25 Hughes AJ, Dunn KM, Chaffee T, et al. Diagnostic and clinical utility of the GAD-2 for screening anxiety symptoms in individuals with multiple sclerosis. Arch Phys Med Rehabil 2018;99:2045-9.

26 Liao Q, Cowling BJ, Lam WWT, et al. Anxiety, worry and cognitive risk estimate in relation to protective behaviors during the 2009 influenza $\mathrm{A} / \mathrm{H} 1 \mathrm{~N} 1$ pandemic in Hong Kong: ten cross-sectional surveys. BMC Infect Dis 2014;14:169.

27 de Zwart O, Veldhuijzen IK, Richardus JH, et al. Monitoring of risk perceptions and correlates of precautionary behaviour related to human avian influenza during $2006-2007$ in the Netherlands: results of seven consecutive surveys. BMC Infect Dis 2010;10:114.

$28 \mathrm{Hu}$ X, Zhang Z, Li N, et al. Self-reported use of personal protective equipment among Chinese critical care clinicians during 2009 H1N1 influenza pandemic. PLoS One 2012;7:e44723.

29 IBM CR. IBM SPSS statistics for windows, version 25.0. Armonk, NY IBM Corp, 2017

30 Federal Employment Agency. Remuneration for the professional category "Dental assistant - professional activities", 2019. Available: https://entgeltatlas.arbeitsagentur.de/entgeltatlas/faces/index.jspx; jsessionid=H4eVO9TSUvZXsXNBsGRU3TSdfzPXXPDRZyhrWsvd uVky8I96UISL!-1097910833?_afrLoop=30858439811184458\& afrWindowMode $=0 \&$ afrWindowld=null\&_adf.ctrl-state $=y 1 q 2 n 104 i$ 1\&beruf=Zahnmedizinische\%20Fachangestellte [Accessed $24 \mathrm{Mar}$ 2021].

31 Federal Ministry of Labor and Social Affairs. SARS-CoV-2 occupational safety and health standard, 2020.

32 Bäuerle A, Steinbach J, Schweda A, et al. Mental health burden of the COVID-19 outbreak in Germany: predictors of mental health impairment. J Prim Care Community Health 2020;11:2150132720953682

33 Olivieri JG, de España C, Encinas M, et al. General anxiety in dental staff and hemodynamic changes over Endodontists' Workday during the coronavirus disease 2019 pandemic: a prospective longitudinal study. J Endod 2021;47:196-203.

34 Uziel N, Meyerson J, Birenzweig Y, et al. Professional burnout and work stress among Israeli dental assistants. Psychol Health Med 2019;24:59-67.

35 Lee C-Y, Wu J-H, Du J-K. Work stress and occupational burnout among dental staff in a medical center. J Dent Sci 2019;14:295-301.

36 Rogowska AM, Kuśnierz C, Bokszczanin A, et al. Stress and coping styles during COVID-19 pandemic in Polish sample of university students. Psychol Res Behav Manag 2020;13:797-811.

37 Robert Koch Institute Federal Statistical Office. Health in Germany, 2008. Available: https://www.rki.de/DE/Content/Gesundhe itsmonitoring/Gesundheitsberichterstattung/GBEDownloadsT/ Psychotherapeutische_Versorgung.pdf?_blob=publicationFile [Accessed 24 Mar 2021].

38 Pabst A, Zeller A-N, Sader R, et al. The influence of the SARS-CoV-2 pandemic on oral and maxillofacial surgery: a nationwide survey among 54 hospitals and 240 private practices in Germany. Clin Oral Investig 2021;25:3853-60.

39 Federal Employment Agency. Orthodontic assistant - Earning potential. Available: https://berufenet.arbeitsagentur.de/berufenet/ faces/index?path=null/kurzbeschreibung/verdienstmoeglichkeiten\& $\mathrm{dkz}=8926$ [Accessed 30 Mar 2021]. 